\begin{tabular}{|c|l|}
\hline Title & Resistance switching properties of molybdenum oxide films \\
\hline Author(s) & A rita, M.; Kaji, H.; Fujii, T.; Takahashi, Y. \\
\hline Citation & $\begin{array}{l}\text { Thin Solid Films, 520(14), 4762-4767 } \\
\text { https://doi.org/40.1016/.tsf.2011.10.174 }\end{array}$ \\
\hline Issue Date & 2012-05-01 \\
\hline Doc URL & http://hdl.handle.net/2115/49517 \\
\hline Type & article(author version) \\
\hline File Information & TSF520-14_4762-4767.pdf \\
\hline
\end{tabular}

Instructions for use 


\title{
Resistance switching properties of molybdenum oxide films
}

\author{
M. Arita*, H. Kaji, T. Fujii, Y. Takahashi \\ Graduate School of Information Science and Technology, Hokkaido University \\ Kita-14, Nishi-9, Kita-ku, Sapporo 060-0814, Japan \\ * Corresponding author. Tel.: +81 117066456 Fax: +81 117966457 \\ E-mail address: arita@nano.ist.hokudai.ac.jp
}

\begin{abstract}
Resistive random access memory (ReRAM) properties in which the resistance of the insulating material drastically changes by voltage application have recently attracted much attention. In this work, molybdenum oxide prepared by thermal oxidation of Mo films was studied to investigate its potential as a material exhibiting ReRAM switching. The samples oxidized between 400 and $600{ }^{\circ} \mathrm{C}$ were composed of $\mathrm{MoO}_{3}$ and were switchable. Current-to-voltage curves, which were measured in air at room temperature by using a Pt-Ir probe as the top electrode, indicated the yielding of both the monopolar and bipolar switching properties. The resistance on-off ratio was between 10 and $10^{2}$.
\end{abstract}

\section{Key Words}

Resistance switching memory, ReRAM, Non-volatile memory, $\mathrm{MoO}_{3}$, Binary metal oxide 


\section{Introduction}

Resistive switching random access memory (ReRAM) has attracted much attention as a candidate for next generation memory due to its high density, fast response, low power consumption characteristics as well as for its non-volatility [1-3]. It has a simple capacitor structure of top electrode (TE)/switching layer/bottom electrode (BE), and its resistance changes by more than 10 times with voltage application. Many oxides have been used as the switching layer constituting the metal-oxide-metal (MOM) structure.

ReRAMs are classified into two categories. One of them is monopolar (also called unipolar or nonpolar), where the resistance switch (RS) occurs by voltage with a single polarity. Usually, oxides are initially in a high resistance state (HRS), so a forming process is needed to initialize ReRAMs, which is achieved by applying high voltage $\left(V_{\mathrm{f}}\right)$ to the MOM structure with appropriate current compliance. The film is then converted into a low resistance state (LRS). Afterward, voltage $V_{\mathrm{r}}(<$ $V_{\mathrm{f}}$ ) is applied to the film in LRS with no current limitation, and the state changes to HRS (reset process). Finally, HRS returns back to LRS by applying voltage $V_{\mathrm{s}}\left(V_{\mathrm{r}}<V_{\mathrm{s}}<V_{\mathrm{f}}\right.$ ) with current limitation (set process). The reproducible RS is achieved by repeating the set and reset processes. The second type is bipolar, where the alternation of the input voltage induces RS. The forming process requirements depend on the material.

To use the current test devices as real memories, it is necessary to clarify the switching mechanism. Therefore, huge amounts of research—mainly based on electric measurements—have been conducted, and a few models have been proposed [1-3]. There have also been trials, carried 
out by means of in-situ transmission electron microscopy, to observe the geometric and/or crystallographic change during the switching operation [4-7]. However, the details of the mechanism remain obscure. At the same time, much work and research is currently being carried out to speed up the integration of ReRAM devices [2], so if we look at the future, exploring materials that can be used in ReRAM applications is quite relevant. In addition to the Perovskite-type oxides [8], $\mathrm{NiO}$ [9] and $\mathrm{TiO}_{2}$ [10], which are the most widely investigated oxides in the world, many oxides have recently been reported that show monopoplar and/or bipolar ReRAM switching properties [11-21]. Our present investigation of molybdenum oxide is in this same research category.

Molybdenum trioxide $\left(\mathrm{MoO}_{3}\right)$ is the most stable molybdenum oxide and has been intensively investigated in the research fields of electrochromism, gas sensors, catalyses, etc. [22-24]. Some materials invetigated in these research fields, such as $\mathrm{TiO}_{2}$ and $\mathrm{WO}_{3}$, are paid attention as materials also for ReRAMs. Because of similarity of the application fields, $\mathrm{MoO}_{3}$ is expected to be applied as a ReRAM material. However, such reports are quite rare [21]. In this work, we fabricated thermally oxidized molybdenum oxide films prepared under several conditions and then investigated the ReRAM properties. The results clearly showed the coexistence of monopolar and bipolar switching. This demonstrates that molybdenum oxide is one of the candidates to be studied in terms of ReRAM development.

\section{Experimental Details}


All of the films used in this work were prepared on thermally oxidized Si (001) wafers by radio frequency $(\mathrm{RF})$ magnetron sputtering at room temperature (RT), as shown in Fig. 1. First, a 100-nm-thick Pt film was deposited as a bottom electrode (BE) with a thin Ti adhesion layer. Next, a 100-nm-thick Mo film was deposited on the BE. The RF power was $100 \mathrm{~W}$ for Pt and Ti and 50 W for Mo. The distance of the target and the substrate was $95 \mathrm{~mm}$. The sample was then thermally oxidized in air at $300-800{ }^{\circ} \mathrm{C}$ for 10 minutes using a muffle-type electric furnace. The formation of the polycrystalline oxides was studied by X-ray diffractometry using an ordinary diffratometer with a graphite monochrometer (XRD, $\theta$-2 $\theta$ method, Rigaku RINT 2200VK/PC) and X-ray photoelectron spectroscopy (XPS, Shimadzu ESCA-3400). The X-rays used were CuK $\alpha$ (40 kV, 20 $\mathrm{mA})$ and $\mathrm{MgK} \alpha(10 \mathrm{kV}, 20 \mathrm{~mA})$, respectively. The thickness profiles were measured after $\mathrm{Ar}^{+}(2$ $\mathrm{kV}, 20 \mathrm{~mA}$ ) sputtering processes. The surface morphology was investigated by scanning electron microscopy (SEM) using Hitachi S-4800 operated at $5 \mathrm{kV}$.

The ReRAM properties of the films were investigated using a Pt-Ir probe as a top electrode (TE) (Fig. 1). As a result, a simple metal (Pt-Ir TE)/oxide $\left(\mathrm{MoO}_{3}\right) /$ metal (Pt BE) capacitor structure is obtained. The contact size was about $\phi 10-\phi 20 \mu \mathrm{m}$. Measurements were performed using a Yokogawa GS610 source meter in air at RT (humidity: 20-45\%). The voltage used in the following figures was the potential of the Pr-Ir probe against BE (when no special comment is made).

\section{Results and Discussion}

\subsection{Oxidation of Mo films}


While the sample oxidized at $300{ }^{\circ} \mathrm{C}$ showed no color change from the as-deposited film, those oxidized at temperatures between 400 and $600{ }^{\circ} \mathrm{C}$ exhibited interference colors $\left(400{ }^{\circ} \mathrm{C}\right.$ : dark goldenrod, $500{ }^{\circ} \mathrm{C}$ : violet, $600{ }^{\circ} \mathrm{C}$ : emerald green). In other words, adequate oxidation was achieved above $400{ }^{\circ} \mathrm{C}$. The samples oxidized at 500 and $600{ }^{\circ} \mathrm{C}$ were somewhat whitish because of diffused reflection caused by the surface roughness due to the crystal growth of the oxide. The films at 700 and $800{ }^{\circ} \mathrm{C}$ were almost completely sublimated after oxidation for 10 minutes.

XRD patterns are presented in Fig. 2. To prevent any contribution from the Si (001) substrate, the measurements were performed with an offset $\theta$ angle of $3.5^{\circ}$. Only the 110 peak of Mo (110 Mo, indicated by gray circles) was recognized in both the as-deposited and $300{ }^{\circ} \mathrm{C}$ samples (Figs. 2a and b). At $400{ }^{\circ} \mathrm{C}$, faint peaks corresponding to 200 , 400, and 810 reflections of the orthorhombic $\mathrm{MoO}_{3}$ (full circles; JCPDS No. 5-508) were detected (Fig. 2c). By increasing the oxidation temperature to $500{ }^{\circ} \mathrm{C}$, the $110_{\text {Mo }}$ reflection was significantly weakened and the reflection peaks corresponding to $\mathrm{MoO}_{3}$ appeared clearly (Fig. 2d). At $600{ }^{\circ} \mathrm{C}$, the sample was completely converted to $\mathrm{MoO}_{3}$ (Fig. 2e). Since $111_{\mathrm{Pt}}$ and $110_{\mathrm{Mo}}$ are very close to each other, only films without the Pt layer are presented in this figure. The films with the Pt layer that were used for electric measurements showed the same result.

XPS measurements were performed to determine the depth profile of the molybdenum oxide films. As shown in Fig. 3, where the platinum signal (light gray square) originates from the BE, the rising temperature increased the oxide layer thickness. At $300{ }^{\circ} \mathrm{C}$, the oxygen signal (gray circle) is high only near the surface while the molybdenum signal (open circle) is high inside the film (Fig. 
3a). The increase of the oxygen signal after 400 minutes of sputtering is due to the $\mathrm{SiO}_{2}$ layer used as the substrate. In this case, only the surface region was oxidized. With oxidation at $400{ }^{\circ} \mathrm{C}$, the thickness of the oxide layer increased (Fig. 3b). At 500 and $600{ }^{\circ} \mathrm{C}$ (Figs. 3c and d), the films seem to be almost completely oxidized, although the XRD pattern of the $500{ }^{\circ} \mathrm{C}$ sample contained a weak peak of metallic Mo. The samples at 700 and $800{ }^{\circ} \mathrm{C}$ did not show the Mo signal because the oxide was sublimated.

The corresponding surface morphology was investigated by SEM (Fig. 4). While the film surface was smooth at $300{ }^{\circ} \mathrm{C}$ (Fig. $4 \mathrm{a}$ ), it became rougher at $400{ }^{\circ} \mathrm{C}$ when the oxidation at the surface was more fully complete (Fig. 4b). At the temperature where the films were almost fully oxidized, crystal growth of the oxide was clearly visible (Figs. 4c and d), which corresponds well to the XRD pattern (Figs. 3d and e).

To summarize the above results, the oxidation of the Mo films occurred at temperatures higher than $300{ }^{\circ} \mathrm{C}$. We know that the obtained oxide was $\mathrm{MoO}_{3}$, but details about the oxygen deficiency remain obscure. Since $\mathrm{MoO}_{3}$ is volatile, the films were fatally sublimated at temperatures higher than $600{ }^{\circ} \mathrm{C}$. These results are in agreement with earlier reports on the oxidation process of bulk Mo [25-27].

\subsection{ReRAM switching property}

Electric properties were measured using the samples oxidized at 400,500 , and $600{ }^{\circ} \mathrm{C}$. The initial resistances of the films estimated using the average slope of the current-to-voltage (I-V) curve 
between 0 and $+1 \mathrm{~V}$ were summarized in Fig. 5 . Raising the oxidation temperature, the resistance increased similarly to the result in an earlier report on $\mathrm{NiO}[28,29]$. This is thought to relate to the increments of the degree of oxidation and the oxide layer thickness at higher temperature.

By applying voltage with a current compliance to the film in the initial HRS, the resistance abruptly changed to LRS at a threshold voltage $\left(V_{\text {th }}\right)$. After this procedure, the samples tended to show ReRAM switching properties while no switching was occasionally observed. In the former case, $V_{\text {th }}$ correspond to the forming voltage $\left(V_{\mathrm{f}}\right)$. The $V_{\text {th }}$ value of the sample oxidized at $400{ }^{\circ} \mathrm{C}$ was around $1.8 \mathrm{~V}$, and RS was hard to be observed probably because the oxide layer was too thin for the measurement using the probe-type top electrode. By increasing the oxidation temperature to $500{ }^{\circ} \mathrm{C}$, $V_{\text {th }}$ was between 2 and $3 \mathrm{~V}$. Coexistence of the monopolar and the bipolar switching was recognized within one sample as reported in earlier works on binary metal oxides [30-37], although the condition (e.g. current compliance value and maximum voltage to be applied) to realize RS with high probability is still obscure in detail. At $600{ }^{\circ} \mathrm{C}, V_{\text {th }}$ was further increased to the value larger than $3 \mathrm{~V}$. In this case, the switching was unstable probably because of the higher power injection at large $V_{\text {th}}$. In the following subsections, therefore, the sample oxidized at $500{ }^{\circ} \mathrm{C}$ is used for discussion, in which the ReRAM properties were most frequently observed among the three samples.

\subsubsection{Monopolar switching}

An example of monopolar switching is shown in Fig. 6. The $I-V$ curve (Fig. 6a) showed 
typical features, and the application of high voltage (between +1 to $+2 \mathrm{~V}$ ) with a current compliance changed HRS to LRS (set process). Subsequent low voltage application (between +0.5 to $+1 \mathrm{~V}$ ) without a current compliance converted LRS to HRS (reset process). A log-log plot of current and voltage is shown in Fig. 6b to determine the conduction type of LRS and HRS. The slope of the data for LRS was almost 1, indicating an ohmic conduction. This points to a filament type conduction, as has widely been assumed [1-3]. In contrast, the slope for HRS was 1.1 at lower voltage and 1.4 at higher voltage. This corresponds with an earlier report in which the authors suggested the weak space-charge-limited conduction [35]. Although the details are obscure, a similar phenomenon might have occurred in the present work. Endurance property is summarized in Fig. 6c. The resistance on-off ratio was 10-100, although the stability was not yet good enough.

\subsection{Bipolar switching}

Figure 7a shows a typical bipolar hysteresis of the 1st and the 2nd cycles from the initial state.

By raising the voltage to about $3 \mathrm{~V}$, the current abruptly increased (process 1 , forming). The bipolar hysteresis of the Mo oxide requires a forming process. In process 2, reducing the voltage, the film showed a nonlinear feature, which is the HRS of the bipolar switching. By applying a negative voltage of about $-0.7 \mathrm{~V}$, the resistance decreased (process 3 with current increase). This is LRS. Afterward, the $I-V$ curve was linear (process 4). In the 2nd cycle, LRS (processes 5 and 8) and HRS (processes 6 and 7) were alternated. To check the influence of the voltage polarity, the measurement was started using a negative voltage as shown in Fig. 7b. No forming occurred down to - 3V. When 
the voltage was applied positively, the forming occurred at $2.7 \mathrm{~V}$. When the TE was positively biased, the resistance changed from LRS to HRS, and vice versa. This feature corresponds to that of a $\mathrm{TE}(\mathrm{Pt}) / \mathrm{TiO}_{2} / \mathrm{TiO}_{2-\mathrm{x}} / \mathrm{BE}(\mathrm{Pt})$ stacking device [33]. In the present work, the oxide surface was exposed to air. The surface seemed to be more highly oxidized than the inner part of the film, and thus the ReRAM structure was expected to be TE(Pt-Ir)/MoO $/ \mathrm{MoO}_{3-\delta} / \mathrm{BE}(\mathrm{Pt})$, which is the same structure as the one in ref. 12. In the forming process corresponding to Fig. 7b, the application to 4V changed the initial HRS to LRS. However, the resistance remained in LRS by applying the positive voltage, and no bipolar switching was realized. Repeated $I-V$ cycles are shown in Fig. 8a, and sequential change of resistance was seen as shown in Fig. 7. An interesting point is the existence of a dip in the positive bias region (between processes 1 and 2). When this dip appeared, the hysteresis cycles tended to be stable. We carefully re-examined other reports and found that such dips have occasionally been seen [e.g., 17, 31]. The endurance property is shown in Fig. 8. A resistance on-off ratio of about 10 was achieved though a misreading occurred at cycle 23. As shown in Fig. 9, process 5 (LRS) and process 6 (HRS) in Fig. 7a were analyzed to check the conduction type. The LRS log-log plot showed a linear relation with a slope of 1 (Fig. 9a). This is an ohmic conduction, as in the LRS of the monopolar switching. In contrast, the curve of HRS is quite bent. On the basis of discussions in earlier works [38], we considered the Poole-Frenkel effect [39], which follows the following equation:

$$
J \propto E \exp \left[\frac{-q\left(\phi_{B}-\sqrt{q E / \pi \varepsilon}\right)}{k_{B} T}\right],
$$


where $J$ is the current density, $E$ the electric field, $q$ the elementary charge, $\phi_{\mathrm{B}}$ the voltage barrier, $\varepsilon$ the dynamic permittivity, $k_{\mathrm{B}}$ Boltzmann's constant, and $T$ the temperature. A corresponding graph is shown in Fig. 9b where the current $I$ and the voltage $V$ were used instead of $J$ and $E$. The graph was linear with a slope of 1 . The conduction of HRS can be described by the Pool-Frenkel type hopping conduction probably caused by defects such as oxygen-deficient sites while the Shottky effect which gives the similar relation must also be considered.

\section{Summary and Conclusion}

The ReRAM properties of thermally oxidized molybdenum oxide films were investigated through $I-V$ measurements. The 100 -nm-thick Mo film was almost completely converted to an orthorhombic $\mathrm{MoO}_{3}$ structure by oxidation in air at 500 and $600{ }^{\circ} \mathrm{C}$ for 10 minutes. The samples oxidizes at $500{ }^{\circ} \mathrm{C}$ exhibited both monopolar and bipolar switching properties. A part of the Mo layer of this sample remained without oxidation as recognized in Fig. 2d. This means the layer stacking was Pt-Ir/MoO $3 / \mathrm{Mo}$ instead of Pt-Ir/ $\mathrm{MoO}_{3} / \mathrm{Pt}$. Although the details are obscure, this stacking structure may have a possibility to realize the coexistence. The coexistence of these properties have also been reported in other binary oxides [32, 33, 35, 38]. The molybdenum oxide is thought to be a promising candidate for study in the field of ReRAM research. At present, the reproducibility and stability of the ReRAM switching are not good enough, probably because the measurement system used a probe-type TE. Studies using well established TE/MoO $/ \mathrm{BE}$ devices will be required to discuss about the problems in the future. 


\section{Acknowledgements}

The XRD measurements were performed at High Brilliance X-ray Laboratory, Hokkaido University.

This work was done in collaboration with the Semiconductor Technology Academic Research

Center. Our research was partially supported by a grant for the Global COE Program, "Center for

Next-Generation Information Technology based on Knowledge Discovery and Knowledge

Federation,” from the Ministry of Education, Culture, Sports, Science and Technology of Japan, and by KAKENHI from MEXT and JSPS in Japan (Nos. 21560681 and 22240022).

\section{References}

[1] A. Sawa, Mater. Today 11 (2008) 28.

[2] H. Akinaga, H. Shima, Proc. IEEE 98 (2010) 2237.

[3] R. Waser, R. Dittmann, M. Salinga, M. Wuttig, Solid State Electron. 54 (2010) 830.

[4] D.-H. Kwon, K. M. Kim, J. H. Jang, J. M Jeon, M. H. Lee, G. H. Kim, X.-S. Li, G.-S. Park, B. Lee, S. Han, M. Kim, C. S. Hwang, Nat. Nanotechnol. 5 (2010) 148.

[5] H. Schroeder, R. Pandian, J. Miao, Phys. Stat. Solidi A 208 (2011) 300.

[6] T. Fujii, M. Arita, K. Hamada, H. Kondo, H. Kaji, Y. Takahashi, M. Moniwa, I. Fujiwara, T. Yamaguchi, M. Aoki, Y. Maeno, T. Kobayashi, M. Yoshimaru, J. Appl. Phys. 109 (2011) 053702.

[7] T. Fujii, M. Arita, Y. Takahashi, I. Fujiwara, Appl. Phys. Lett. 98 (2011) 212104. 
[8] S. Q. Liu, N. J. Wu, A. Ignatiev, Appl. Phys. Lett. 76 (2000) 2749.

[9] S. Seo, M. J. Lee, D. H. Seo, E. J. Jeoung, D.-S. Suh, Y. S. Joung, I. K. Yoo, I. R. Hwang, S. H. Kim, I. S. Byun, J.-S. Kim, J. S. Choi, B. H. Park, Appl. Phys. Lett. 85 (2004) 5655.

[10] B. J. Choi, D. S. Jeong, S. K. Kim, C. Rohde, S. Choi, J. H. Oh, H. J. Kim, C. S. Hwang, K. Szot, R. Waser, B. Reichenberg, S. Tiedke, J. Appl. Phys. 98 (2005) 033715.

[11] H. Shima, F. Takano, H. Akinaga, Y. Tamai, I. H. Inoue, H. Takagi, Appl. Phys. Lett. 91 (2007) 012901.

[12] H.-Y. Lee, P.-S. Chen, C.-C. Wang, S. Maikap, P.-J. Tzeng, C.-H. Lin, L.-S. Lee, M.-J. Tsai, Japn. J. Appl. Phys. 46 (2007) 2175.

[13] S. Muraoka, K. Osano, Y. Kanzawa, S. Mitani, S. Fujii, K. Katayama, Y. Katoh, Z. Wei, T. Mikawa, K. Arita, Y. Kawashima, R. Azuma, K. Kawai, K. Shimakawa, A. Odagawa, T. Takagi, Tech. Dig. Int. Electron Devices Meet. (2007) 779.

[14] A. Chen, S. Haddad, Y. C. Wu, T. N. Fang, S. Kaza, Z. Lan, Appl. Phys. Lett. 92 (2008) 013503.

[15] X. Sun, B. Sun, L. Liu, N. Xu, X. Liu, R. Han, J. Kang, G. Xiong, T. P. Ma, IEEE Elect. Dev. Lett. 30 (2009) 334.

[16] M. K. Yang, J.-W. Park, T. K. Ko, J.-K. Lee, Appl. Phys. Lett. 95 (2009) 042105.

[17] B. Sun, L. Liu, N. Xu, B. Gao, Y. Wang, D. Han, X. Liu, R. Han, J. Kang, Japn. J. Appl. Phys. 48 (2009) 04C061.

[18] E.-K. Lai, W.-C. Chien, Y.-C. Chen, T.-J. Hong, Y.-Y. Lin, K.-P. Chang, Y.-D. Yao, P. Lin, S.-F. 
Horng, J. Gong, S.-C. Tsai, C.-H. Lee, S.-H. Hsieh, C.-F. Chen, Y.-H. Shih, K.-Y. Hsieh, R. Liu, C.-Y. Lu, Japn. J. Appl. Phys. 49 (2010) 04DD17.

[19] H.-H. Huang, W.-C. Shih, C.-H. Lai, Appl. Phys. Lett. 96 (2010) 193505.

[20] X. Gao, Y. Xia, B. Xu, J. Kong, H. Guo, K. Li, H. Li, H. Xu, K. Chen, J. Yin, Z. Liu, J. Appl. Phys. 108 (2010) 074506.

[21] D. Lee, D.-J. Seong, H. J. Choi, I. Jo, R. Dong, W. Xiang, S. Oh, M. Pyun. S.-O. Seo, S. Heo, M. Jo, D.-K. Hwang, H. K. Park, M. Chang, M. Hasan, H. Hwang, Tech. Dig. Int. Electron Devices Meet. (2006) S30P8.

[22] N. Miyata, S. Akiyoshi, J. Appl. Phys. 58 (1985) 1651.

[23] G. Laperriere, M.-A. Lavoie, D. Belanger, J. Electrochem. Soc. 143 (1996) 3109.

[24] H. Ohtsuka, Y. Sakurai, Japn. J. Appl. Phys. 40 (2001) 4680.

[25] E. A. Gulbransen, K. F. Andrew, F. A. Brassart, J. Electrochem. Soc. 110 (1963) 952.

[26] N. Floquet, O. Bertrand, Surf. Sci. 251/252 (1991) 1044.

[27] S. I. Castaneda, I. Montero, J. M. Ripalda, N. Diaz, L. Galan, F. Rueda, J. Appl. Phys. 85 (1999) 8415.

[28] H. Kondo, H. Kaji, T. Fujii, K. Hamada, M. Arita, Y. Takahashi, IOP Conf. Series: Mater. Sci. Eng. 8 (2010) 012034.

[29] H. Kondo, M. Arita, T. Fujii, H, Kaji, M. Moniwa, T. Yamaguchi, I. Fujiwara, M. Yoshimaru, Y. Takahashi, Japn. J. Appl. Phys. 50 (2011) 081101.

[30] K. Tsunoda, Y. Fukuzumi, J. R. Jameson, Z. Wang, P. B. Griffin, Y. Nishi, Appl. Phys. Lett. 90 
(2007) 113501.

[31] C. Yoshida, K. Tsunoda, H. Noshiro, Y. Sugiyama, Appl. Phys. Lett. 91 (2007) 223510.

[32] D. S. Jeong, H. Schroeder, R. Waser, Electrochem. Solid-Stat. Lett. 10 (2007) G51.

[33] J. J. Yang, M. D. Pickett, X. Li, D. A. A. Ohlberg, D. R. Stewart, R. S. Williams, Nat. Nanotechnol. 3 (2008) 429.

[34] L. Goux, J. G. Lisoni, M. Jurczak, D. J. Wouters, L. Courtade, Ch. Muller, J. Appl. Phys. 107 (2010) 024512.

[35] J. W. Seo, S. J. Baik, S. J. Kang, Y. H. Hong, J.-H. Yang, L. Fang, K. S. Lim, Appl. Phys. Lett. 96 (2010) 053504.

[36] C. Y. Dong, D. S. Shang, L. Shi, J. R. Sun, B. G. Shen, F. Zhuge, R. W. Li, W. Chen, Appl. Phys. Lett. 98 (2011) 072107.

[37] L. Chen, Q.-Q. Sun, J.-J. Gu, Y. Xu, S.-J. Ding, D. W. Zhang, Curr. Appl. Phys. 11 (2011) 849.

[38] S. Lee, H. Kim, J. Park, K. Yong, J. Appl. Phys. 108 (2010) 076101.

[39] S. M. Sze, K. K. Ng, Physics of Semiconductor Devices, Wiley, New Jersey (2007). 


\section{Figure Captions}

Fig. 1 Schematic drawing of the $\mathrm{MoO}_{\mathrm{x}}$ ReRAM film and the measurement system.

Fig. 2 XRD patterns of Mo films oxidized at various temperatures. (a) as-deposited state and oxidized at (b) $300{ }^{\circ} \mathrm{C}$, (c) $400{ }^{\circ} \mathrm{C}$, (d) $500{ }^{\circ} \mathrm{C}$, and (e) $600{ }^{\circ} \mathrm{C}$. The peak marked by a gray circle is the 110 reflection of metallic Mo. The full circles denote faint $\mathrm{MoO}_{3}$ peaks (200, 400, and 810 reflections).

Fig. 3 XPS depth profiles of films oxidized at (a) $300{ }^{\circ} \mathrm{C}$, (b) $400{ }^{\circ} \mathrm{C}$, (c) $500{ }^{\circ} \mathrm{C}$, and (d) $600{ }^{\circ} \mathrm{C}$. The open and gray circles are signals of Mo and O, respectively, while the light-gray squares correspond to Pt.

Fig. 4 SEM images of films oxidized at (a) $300{ }^{\circ} \mathrm{C}$, (b) $400{ }^{\circ} \mathrm{C}$, (c) $500{ }^{\circ} \mathrm{C}$, and (d) $600{ }^{\circ} \mathrm{C}$. The film surface became rough due to crystal growth of $\mathrm{MoO}_{3}$, especially above $500{ }^{\circ} \mathrm{C}$.

Fig. 5 Initial resistance as a function of oxidation temperature. Data measured at different positions of the samples are summarized. Two samples were tested for each oxidation condition.

Fig. 6 Monopolar switching properties (sample oxidized at $500{ }^{\circ} \mathrm{C}$ for $10 \mathrm{~min}$ ). (a) $I-V$ curve 
showing set and reset processes. (b) The log-log plot of the voltage and the current during the set process where the numbers denote the sequence of voltage application. (c) The endurance property where the resistance was estimated at $0.1 \mathrm{~V}$ by using the $I-V$ curve.

Fig. $7 \quad I-V$ curves showing the bipolar switching (sample oxidized at $500{ }^{\circ} \mathrm{C}$ for $10 \mathrm{~min}$ ), which are the 1st (open circles) and the 2nd (small full circles) cycles from the initial state. The numbers in each figure denote the sequence of the voltage application. The first application of voltage was performed (a) positively and (b) negatively to the Pt-Ir probe.

Fig. 8 Bipolar switching properties (sample oxidized at $500{ }^{\circ} \mathrm{C}$ for $10 \mathrm{~min}$ ). (a) Continuous $I-V$ curves. (b) The endurance property where the resistance was estimated at $\pm 0.1 \mathrm{~V}$ by using the $I-V$ curve.

Fig. 9 The relation between the voltage and the current of (a) LRS and (b) HRS, which correspond to process 5 and process 6 of Fig. 7a, respectively. 


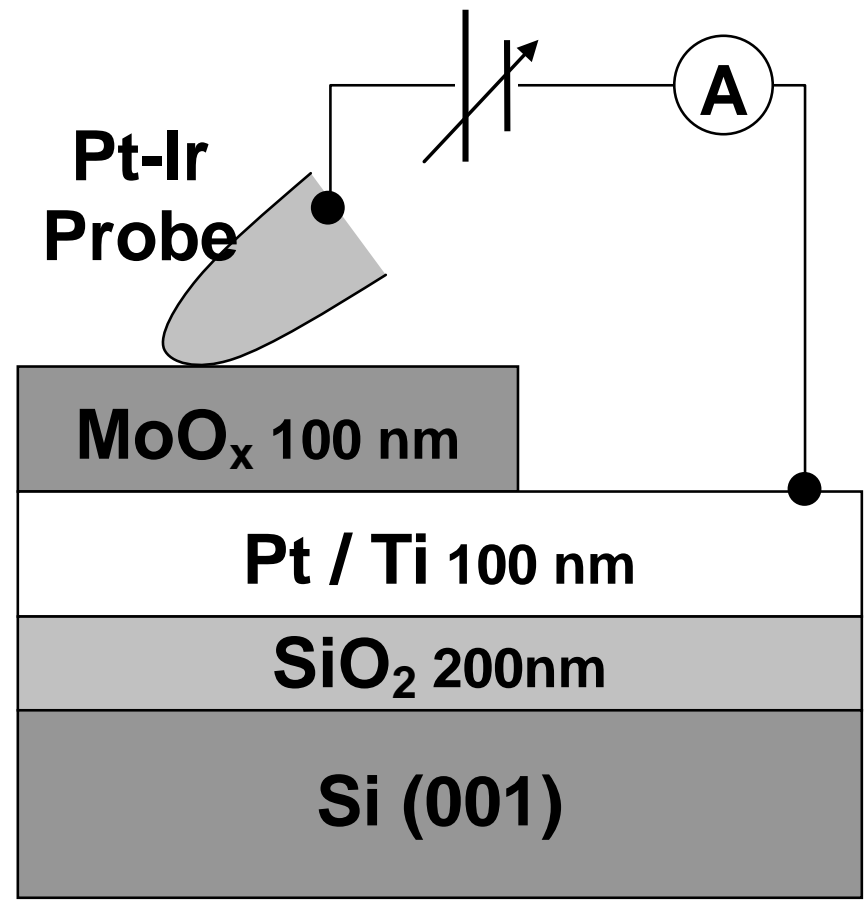

Fig. 1 Arita et.al. 


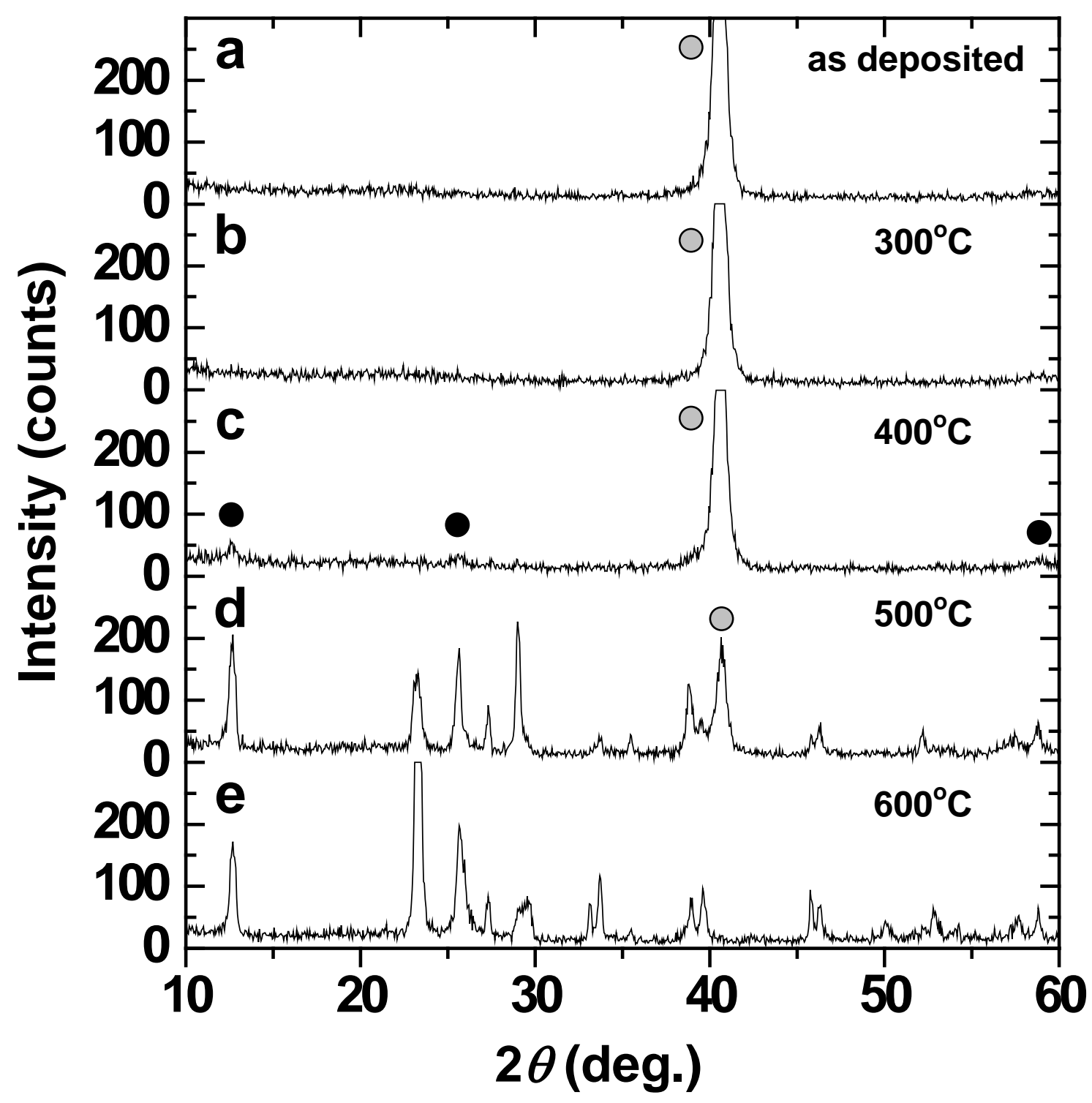

Fig. 2 Arita et.al. 


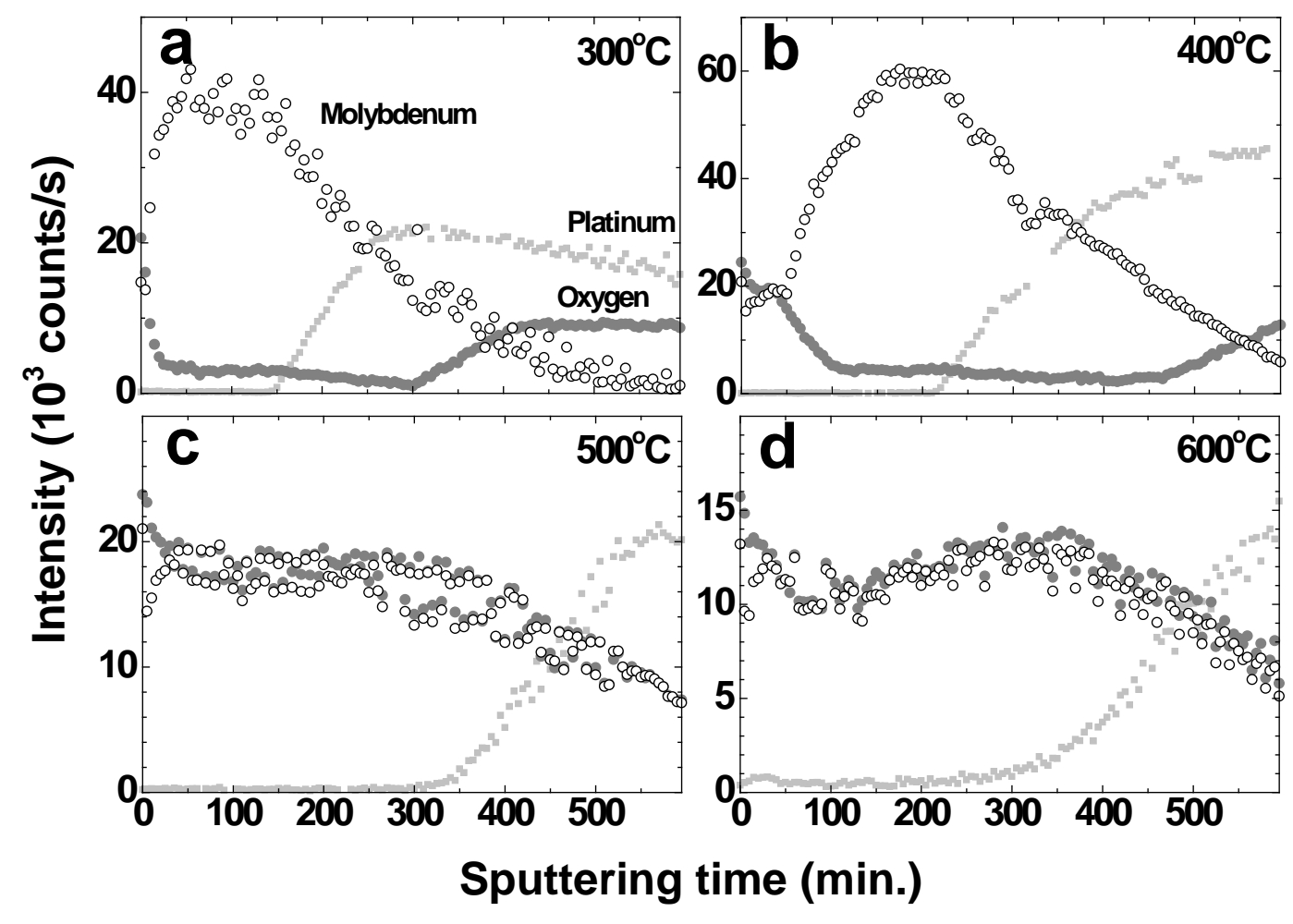

Fig. 3 Arita et.al. 


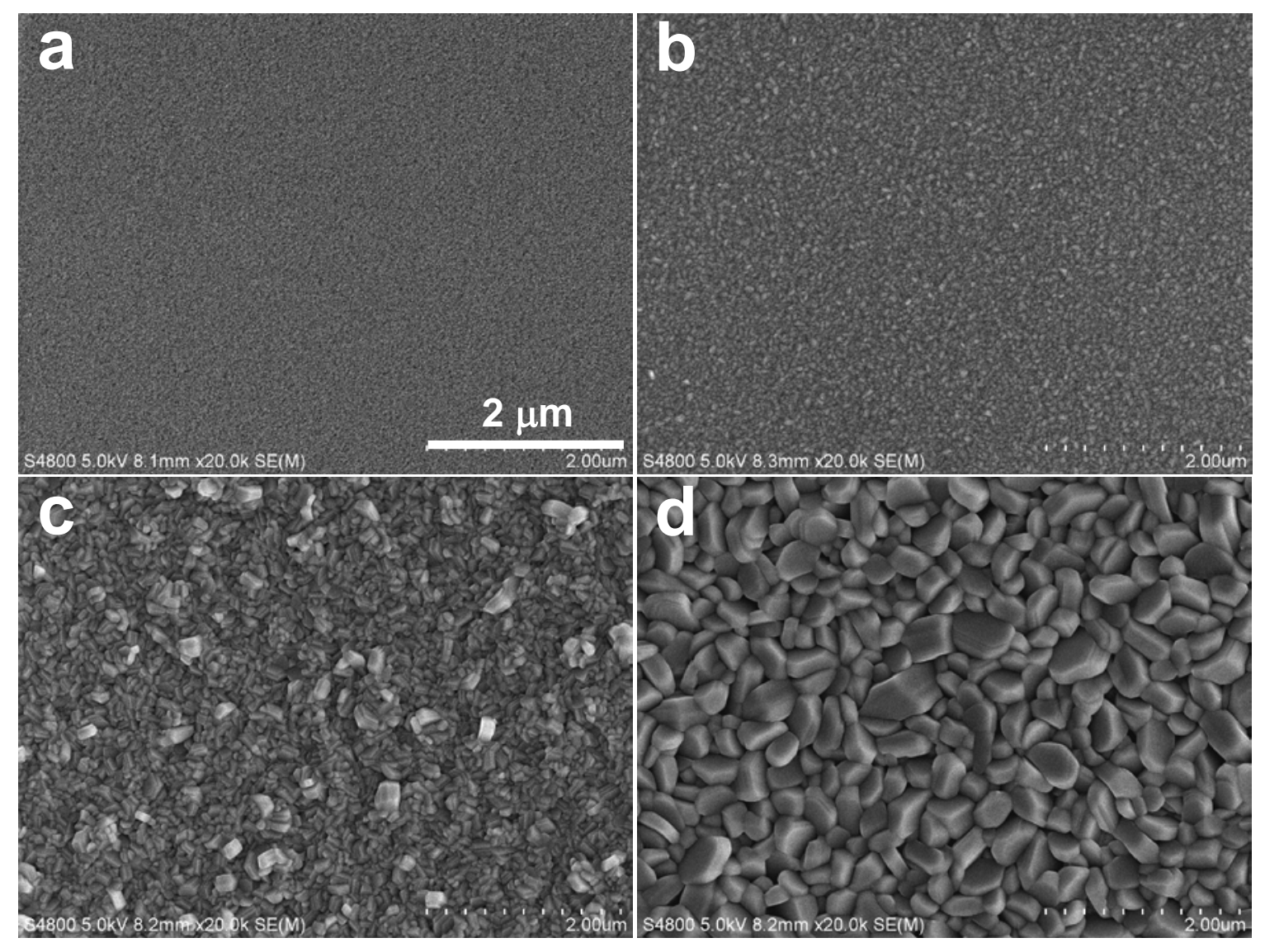

Fig. 4 Arita et.al. 


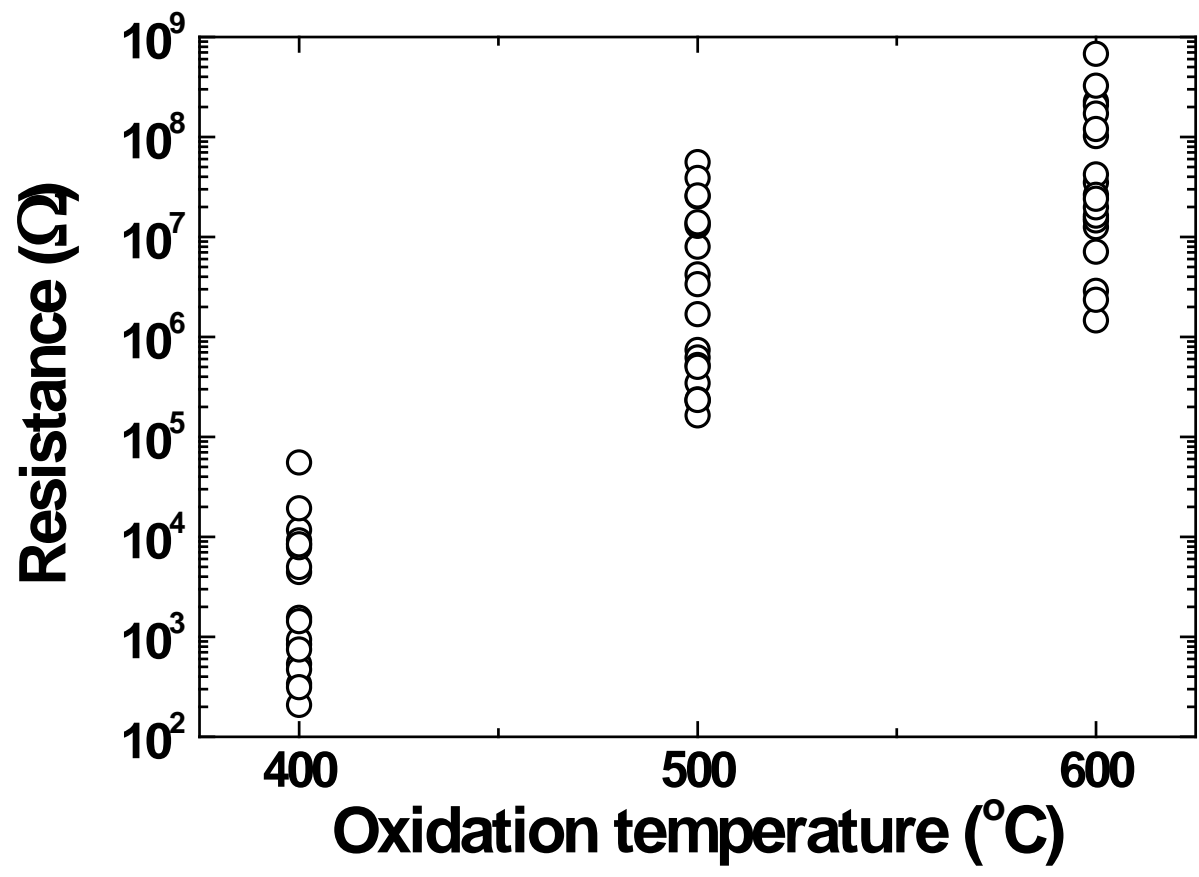

Fig. 5 Arita et.al. 

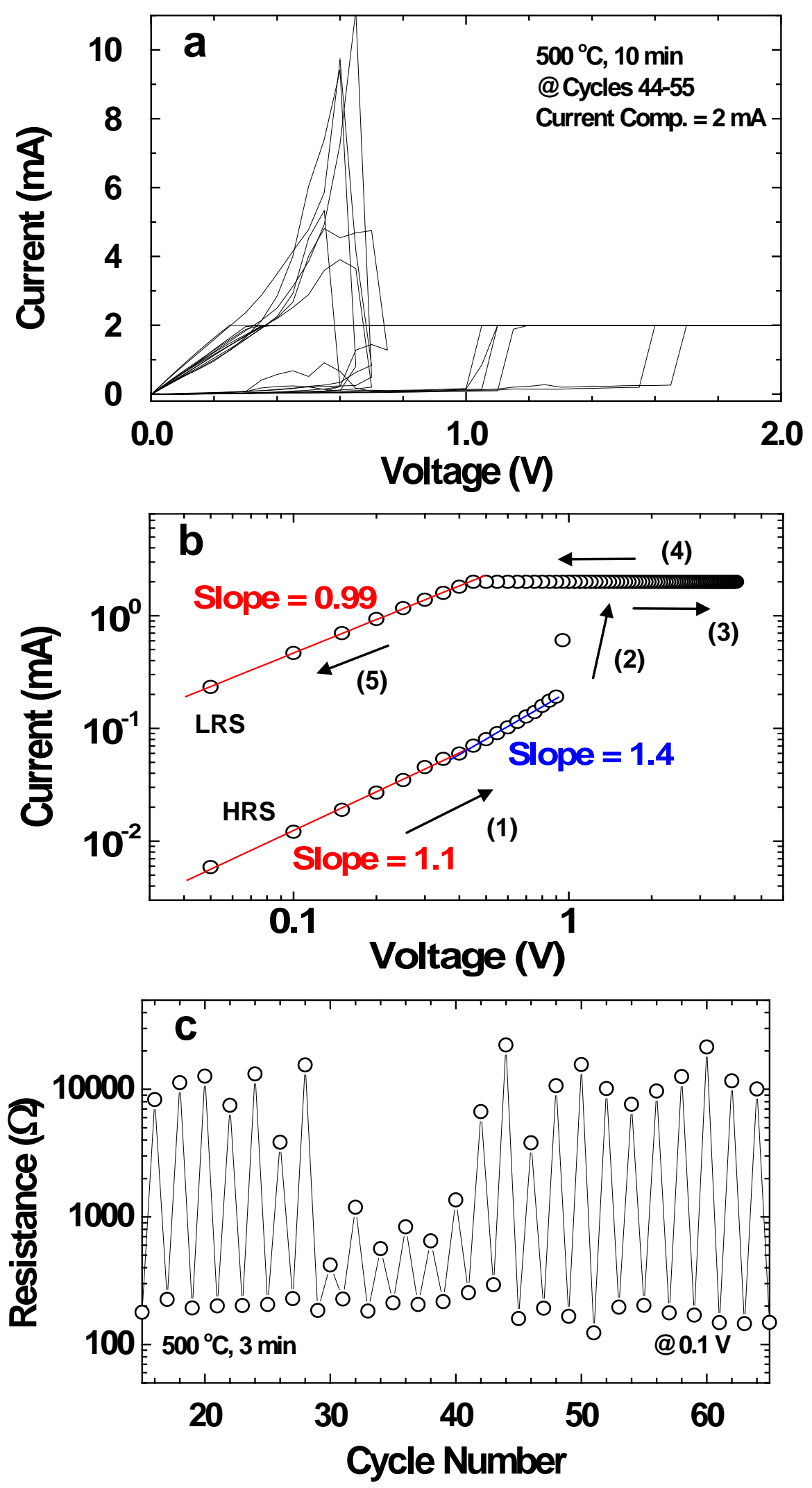

Fig. 6 Arita et.al. 


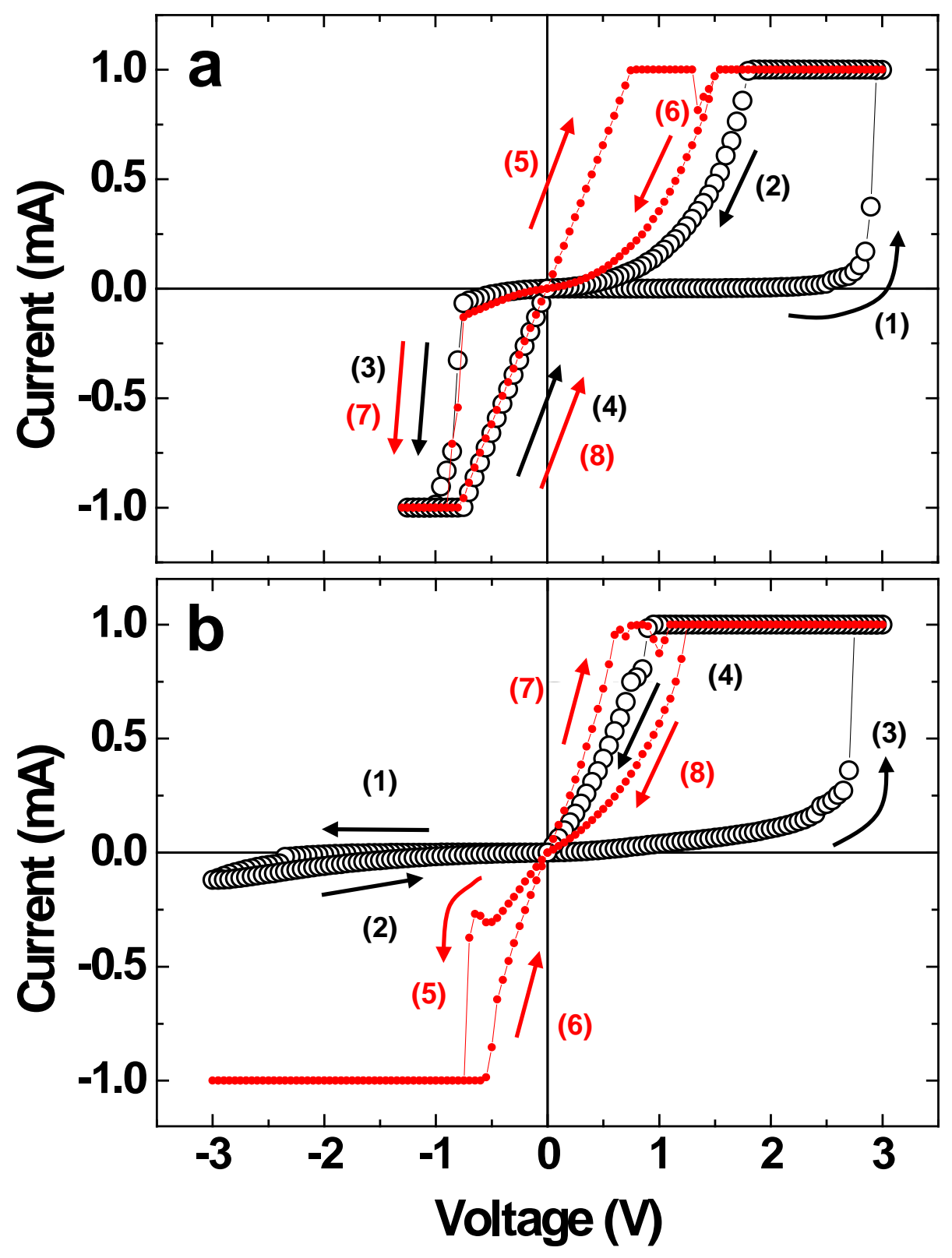

Fig. 7 Arita et.al. 

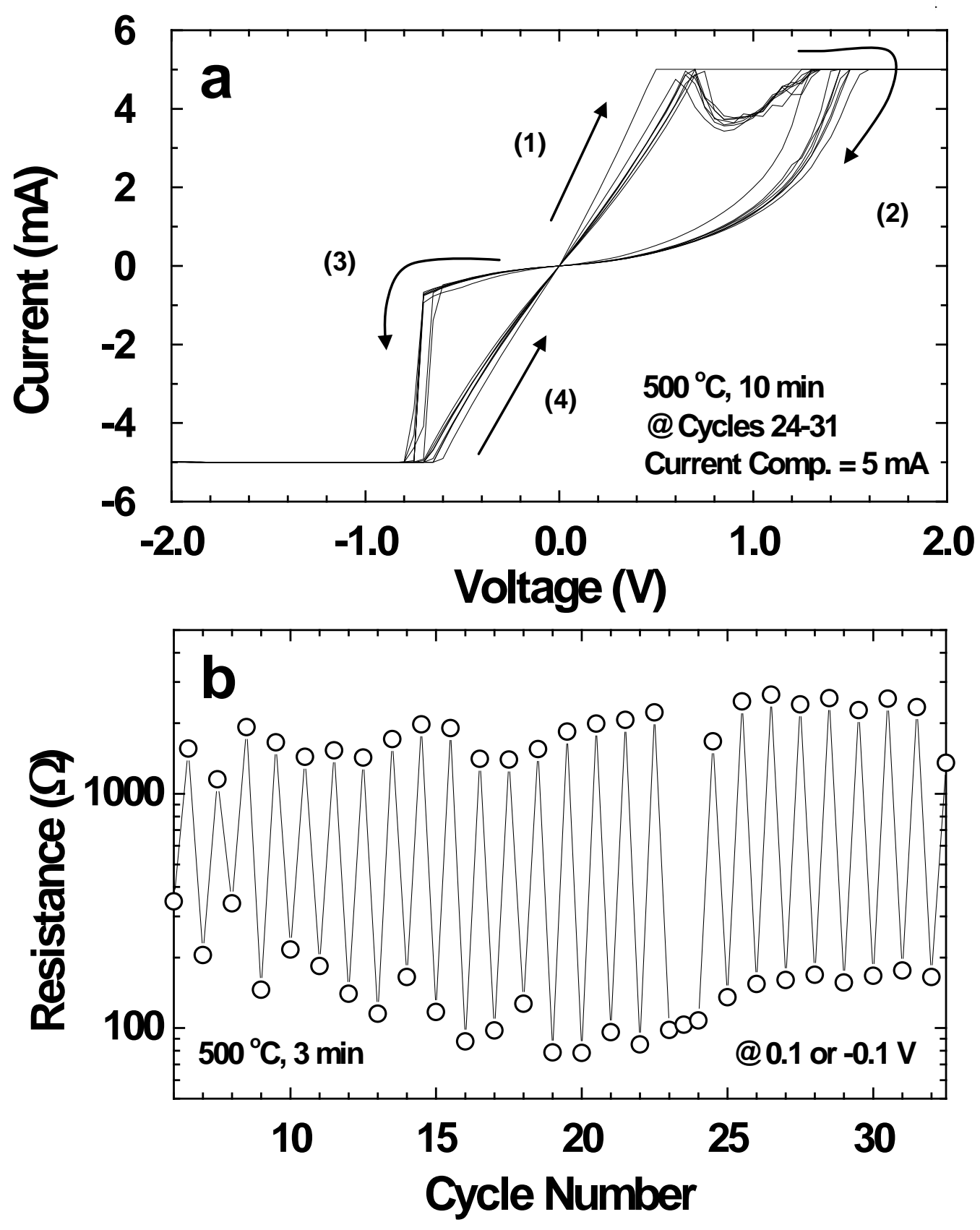

Fig. 8 Arita et.al. 


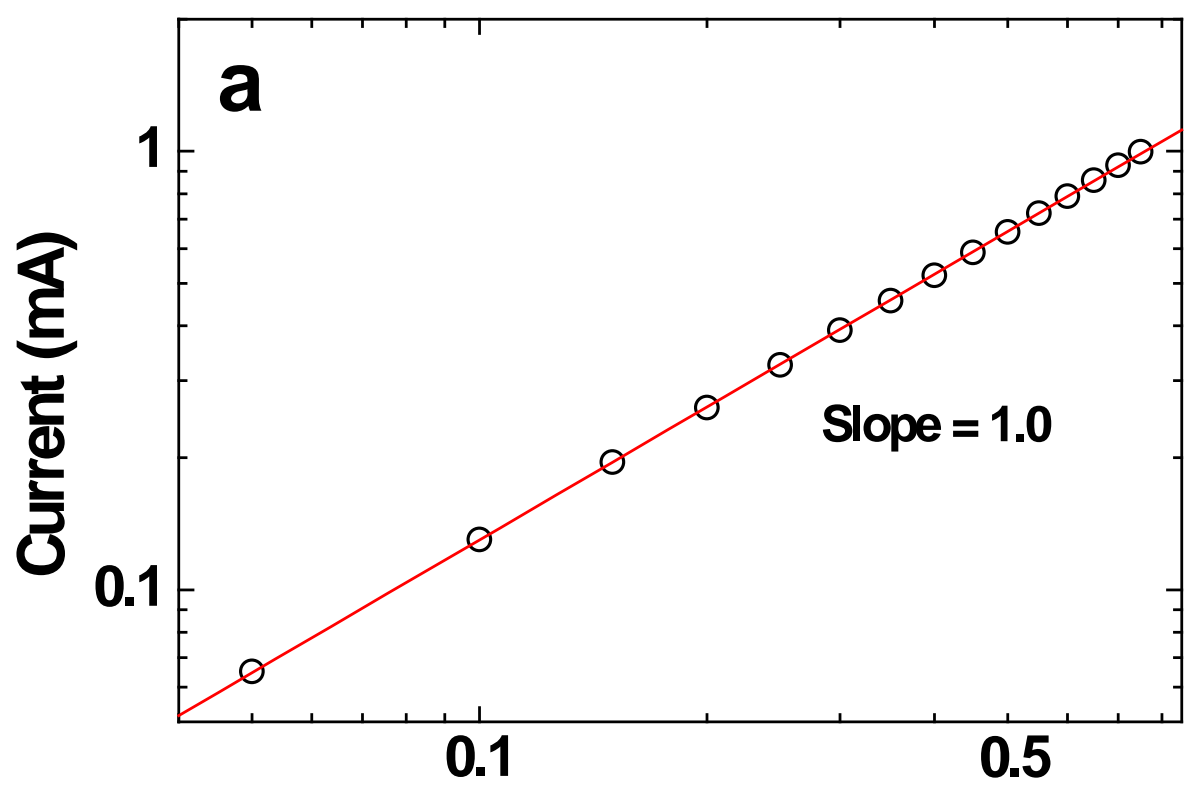

Voltage $(M)$

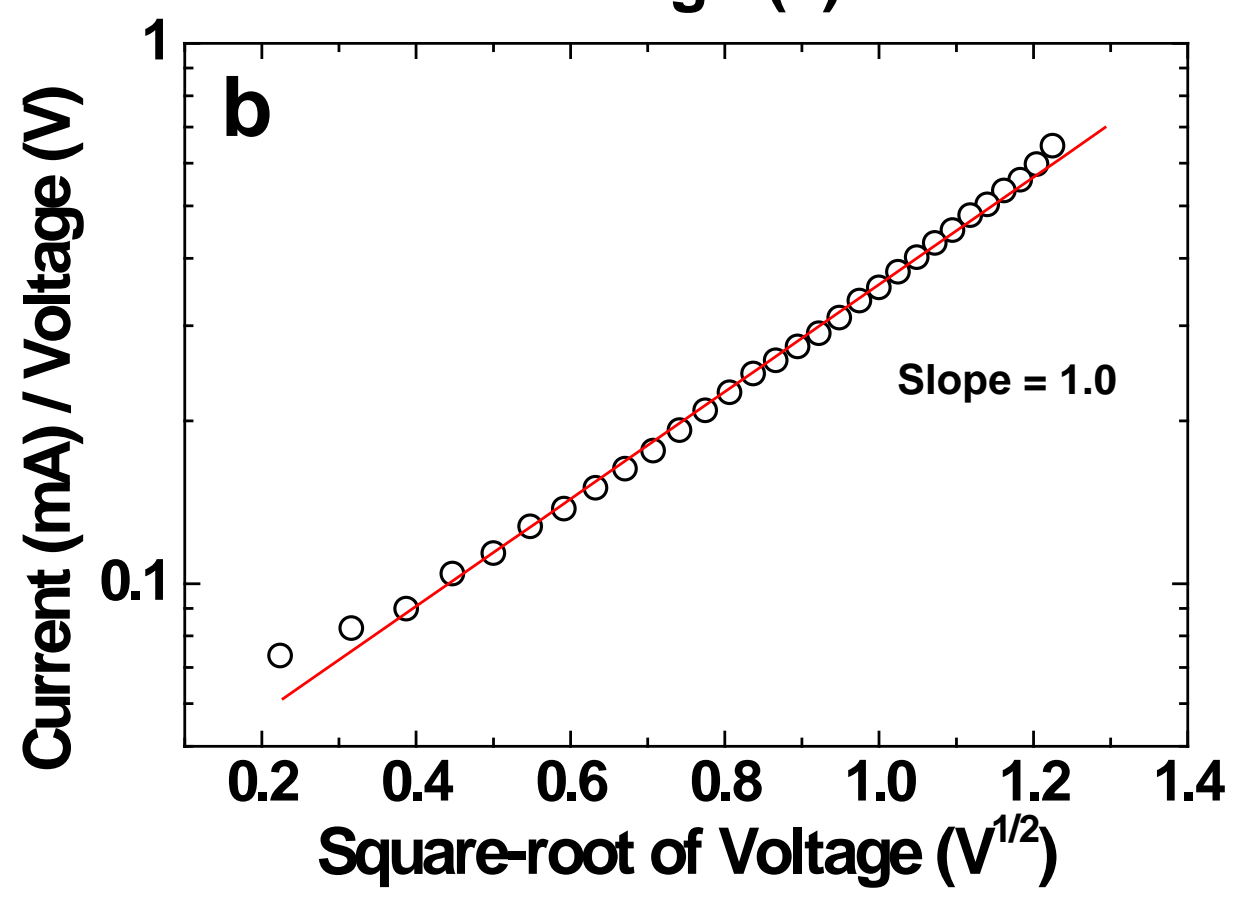

Fig. 9 Arita et.al. 